\title{
大别山山地次生林鸟类群落集团结构的季节变化
}

\author{
刘 涁 $^{1}$, 周立志 ${ }^{1, *}$, 汪文革 ${ }^{2}$, 沈三宝 ${ }^{2}$, 韩德民 ${ }^{1}$ \\ (1. 安徽大学 生命科学学院生物多样性与湿地生态研究所, 安徽省生态工程与生物技术重点实验室, 安徽 合肥 230039; \\ 2. 暚落坪国家级自然保护区管理局, 安徽 岳西 246600)
}

\begin{abstract}
摘要: 2007 年 12 月一-2008 年 12 月, 在大别山鹞落坪, 对落叶阔叶次生林鸟类的集团结构的季节变化特征 进行了研究。采用连续取样法采集鸟类取食行为数据, 用聚类分析法对繁殖和非繁殖季节鸟类群落进行集团划分, 通过无倾向对应分析 (DCA) 对 32 种森林鸟类的两个季节资源利用特点进行了研究。结果表明, 鸟类群落在非 繁殖季节可以分为地面、灌从、树干（枝）、冠层等 4 个取食集团, 而在繁殖季节还出现空中取食集团; 候鸟影 响嫍落坪次生林鸟类群落取食集团的结构, 产生新的取食集团。DCA 的第一轴主要代表鸟类取食高度信息, 第二 轴主要代表鸟类取食位置信息, 第三轴代表鸟类取食方式和取食基质信息; 用 DCA 前两轴对 32 种鸟类排序表明, 有 6 种鸟主要在第一轴发生变化, 有 4 种鸟主要在第二轴发生变化。
\end{abstract}

关键词：鸟类群落；集团结构；季节特征；取食方式；大别山鹞落坪

中图分类号: Q959.7; Q958.15 文献标识码: A 文章编号: 0254-5853-(2009)03-0277-011

\section{Seasonal Dynamics of the Avian Guild Structure of Mountain Secondary Forest in Dabieshan Mountain}

\author{
LIU Bin ${ }^{1}$, ZHOU Li-zhi ${ }^{1, *}$, WANG Wen-ge ${ }^{2}$, SHEN San-bao ${ }^{2}$, HAN De-min ${ }^{1}$ \\ (1. Institute of Biodiversity and Wetland Ecology, School of Life Science, Anhui University; Anhui Key Laboratory of Ecological Engineering \\ and Biotechnique, Hefei 230039, China; 2. Yaoluoping National Natural Reserve, Yuexi 246600)
}

\begin{abstract}
Between December 2007 and December 2008, we studied the avian guilds structure of the secondary broad-leaved forests in Yaoluoping, Dabieshan Mountain, Anhui Province. We used focal sampling method to observe feeding behaviors of the bird community, and collected food resource utilization data. PC-ORD was used in Cluster Analysis for the guild structures in the two seasons, and Detrended Correspondence Analysis (DCA) for the feeding patterns of the 32 birds in both the breeding/non-breeding seasons. Results indicated that during the non-breeding season, the bird community could be divided into four guilds: ground forager, shrub forager, tree trunk (branches) forager, and canopy forager. In addition to the four listed guilds, there was an air foraging guild during the breeding season. The first axis of DCA represented the information of the foraging height, the second axis represented the information of the foraging position, and the third axis represented the information of the foraging pattern and the foraging matrix. The ordination for the 32 birds by the first two DCA axes indicated the behavior of 6 birds mainly changed along the first DCA axis, which represented the change information of the foraging height. Additionally, behavior of 4 birds mainly changed along the second DCA axis, which represented the change information of the foraging position.
\end{abstract}

Key words: Avian community; Guild structure; Seasonal dynamic; Feeding pattern; Yaoluoping National Natural Reserve

鸟类群落中, 环境要素特别是植被和食物资源 的时空动态对于鸟类聚集具有重要影响, 这些影响 通常体现在鸟类群落的结构变化上（Hou et al,
2001)。鸟类群落的集团结构体现群落内物种的资 源分割特征和群落结构组织规律 (Zhou, 1987; Liu \& Han, 2008)。群落内的集团结构也并非一成不变, 
在不同的地区、不同的环境、不同的演替阶段常具 有不同的集团结构（Zhou, 1987; Ding et al, 2007)。 当季节更替鸟类发生聚集时, 集团结构更加不稳 定, 并且经常发生较大变化 (Casenave et al, 2008)。

在森林群落中, 同一时期内鸟类群落的集团结 构相对稳定, 而特定时期鸟类群落的集团结构特征 受到较多关注 (Gao et al, 1990)。研究表明, 鸟类 的集团结构在不同时期是不稳定的（Blondel, 2003; Jaksic，1981)。在森林鸟类群落中, 不同时期的集 团结构的时空动态及其资源利用特征一直是值得 探讨的群落生态学问题。

大别山暚落坪国家级自然保护区, 植被属于典 型的次生森林, 特别是落叶阔叶次生林植物群落四 季外貌变化分明; 而且由于近年来的天然林保护工 程的实施, 植物群落发生变化 (Xu et al, 2003), 因 而该区是研究北亚热带向暖温带过渡带鸟类群落 生态学的理想地点。我们在暚落坪自然保护区内, 选择落叶阔叶次生林, 对鸟类群落结构和取食行为 进行了研究, 以期了解北亚热带向暖温带过渡带山 地次生林鸟类群落的季节动态及其资源利用特征。

\section{1 研究地点和方法}

\section{1 研究地点概况}

鹞落坪自然保护区位于安徽省岳西县包家乡, 北与安徽省霍山县接壤, 西与湖北省英山县毗邻。 地理坐标为 $116^{\circ} 02^{\prime}-116^{\circ} 11^{\prime} \mathrm{E} ; 30^{\circ} 57^{\prime}-31^{\circ} 06^{\prime} \mathrm{N}$ 。 地处大别山主峰江淮分水岭, 境内山峦起伏, 地形 复杂, 海拔落差很大, 最低 $500 \mathrm{~m}$, 最高 $1721.5 \mathrm{~m}$ 。 鸴落坪的气候属于北亚热带季风区, 年平均气温 $11.5^{\circ} \mathrm{C}$, 最冷月 (1 月) 平均气温约 $2^{\circ} \mathrm{C}$, 最热月 $(7$ 月) 平均气温 $22-25^{\circ} \mathrm{C}$, 无霜期 220 天。年平均降 雨量 $1700 \mathrm{~mm}$, 并且季节分配不均, 夏季最多

$(44.2 \%)$, 冬季最少 $(8.9 \%)$ 。

鹞落坪是大别山次生植被保存最好的地区之 一, 区内植被类型多样, 主要有 3 个植被型: 阔叶 林、针叶林、灌丛, 其中阔叶林为该区的主要植被 类型, 分布面积大, 类型多, 林貌和群落结构在四 季中变化明显 (Xie \& Wu, 1995)。

研究地点在鹞落坪国家级保护区的落叶阔叶 林内。根据植被分布特征, 在保护区内, 选择 7 个 具有代表性的样地, 样地面积大小在 $8-10 \mathrm{hm}^{2}$, 作为鸟类的取食行为观察地点。样地大都位于面积 超过 $50 \mathrm{hm}^{2}$ 的阔叶林斑块中, 但其中一个样地所在
的阔叶林斑块中, 乔木被较严重砍伐, 形成林间空 地, 其间的灌木植被生长繁盛, 该样地靠近这些林 间空地。样地内几乎都有山间小溪流过。样地中的 植被在相同海拔（1000-1300m）同一季节有相似 的外貌。但是, 在不同的季节之中, 群落植被的盖 度有很大差异: 秋冬季节由于大部分植物的叶片都 脱落, 因此其植被盖度要比春夏季小。阔叶林中, 乔木层高 6-18 m, 秋冬季盖度 30\%, 春夏季盖度 $70 \%$ 。主要树种有茅栗 (Castanea seguinii)、栓皮 栋（Quercus variabilis）、江南桤木（Alnus trabeculosa)、香果树 (Emmenopterys henryi)、山 合欢 ( Albizia macrophylla)、盐肤木 (Rhus chinensis)、短柄枹 (Quercus glandulifera) 等。灌 木上层高度为 4-6m, 秋冬季盖度为 $30 \%$, 春夏季 为 $70 \%-80 \%$ 左右, 主要树种有杜鹃 (Rhododendron simsii)、山胡椒 (Lindera glauca)、野鸭椿 (Euscaphis japonica）以及一些乔木树种的幼苗等; 灌木下层 高度 $0.5-4 \mathrm{~m}$, 秋冬季盖度为 $20 \%$, 春夏季为 $50 \%$, 主要有阔叶箬竹 (Indocalamus latifolius)、锦带花

(Weigela florida)、三桠乌药 (Lindera obtusiloba)、 粉花野蓄薇 (Rosa multifolia) 等。草本层稀少, 主 要为一些禾本科植物和葓类, 高度 $0-0.5 \mathrm{~m}$; 地面 层为枯枝落叶和腐殖质。

\section{2 研究方法}

1.2.1 数据采集 野外工作从 2007 年 12 月开始, 到 2008 年 12 月下旬结束。其间, 2008 年 2 月、 6 月、9 月没有进行野外调查。由于 10 月调查集中在 下旬, 鸟类的迁入和迁出频繁, 并且调查数据较少, 故删除 10 月数据不用于分析。

每月每个样地进行 1 次鸟类取食行为调查, 每 次 2-3 天。调查时间为上午 5: 30-9: 30, 下午 16: 00 - 18: 00 。取食行为数量化观察每隔 $30 \mathrm{~s}$ 记 录一次, 看到鸟类取食活动发生后, 记录所在的位 置、基质、高度以及取食方式。参考周放、高玮等 的方法 (Zhou, 1987; Gao et al, 1990), 并结合本地 的实际情况, 对各个取食变量定义如下:

取食方式:（1）拾取: 用鲒直接从基质表面取 食静止的或者移动缓慢的食物;（2）探取：用㗒敲 击并穿破树干、粗枝表面或者用爪扒开地面的落叶 或腐殖质，取食基质表面下的食物；（3）飞取：在 空中飞翔时捕捉飞行的昆虫, 或者鼓翼悬停在空中 取食基质上面静止的食物;（4）出击: 栖止于某处, 看到食物时, 迅速飞出捕取, 然后回到原处或者附 
近的地方。

取食位置:（1）远离树干：树冠外 $1 / 2$ 侧的位 置或者空中; (2) 接近树干: 树冠内 $1 / 2$ 侧的位置 以及胸径大于 $13 \mathrm{~cm}$ 的树木主干, 或大于 $6 \mathrm{~cm}$ 的小 树主干位置; (3) 灌从: 树冠层以下, 地面草本层 以上的位置; (4) 地面位置: 草本层和地面枯枝落 叶、腐殖质层等位置。

取食基质:（1）树冠上层: 树冠层上部 $1 / 3$ 处 的枝及枝上着生的叶、花果和芽; (2) 树冠中层: 树冠层中部 $1 / 3$ 处的枝及枝上着生的叶、花果和芽;

(3) 树冠下层: 树冠层下部 $1 / 3$ 处的枝及枝上着生 的叶、花果和芽;（4）小枝：树冠层以下，包括灌 从和草本层中, 所有直径小于 $2 \mathrm{~cm}$ 枝及枝上着生的 叶、花果和芽; (5) 粗枝: 树冠层以下, 包括灌从 和草本层中, 所有直径大于 $2 \mathrm{~cm}$ 而小于 $13 \mathrm{~cm}$ 的枝 及枝上着生的叶、花果和芽;（6）树干：胸径大于 $13 \mathrm{~cm}$ 的树木主干、侧枝，或大于 $6 \mathrm{~cm}$ 的小树主干;

（7）地面: 草本层枝、叶、花果和芽, 地面枯枝 落叶、倒木、腐殖质等; (8) 空中。

取食高度:（1） 0m;（2） 0-1 m;（3） $1-5 \mathrm{~m}$;

(4) 5-10m;（5） $10-15 \mathrm{~m}$;（6）>15m。

1.2.2 数据处理与分析 䍃落坪地区 3 月底之前, 冬候鸟已经基本迁出。冬候鸟在该地区的活动时间 集中在 11 月初至 4 月初之间, 因此, 将这一时期 归为非繁殖季节, 4 月至 8 月归为繁殖季节。非繁 殖季节共调查 5 个月，分别为 2007 年 12 月, 2008 年 $1 、 3 、 11 、 12$ 月; 繁殖季节共调查 4 个月, 分 别为 2008 年 $4 、 5 、 7 、 8$ 月。

将观察到取食行为的鸟类按照留居型划分为 留鸟、冬候鸟和夏候鸟。将留鸟的取食行为划分为 繁殖季节和非繁殖季节, 冬候鸟的取食行为数据归 为非繁殖季节, 夏候鸟的取食行为数据归为繁殖季 节。由于两种候鸟的迁徙在时间上有交叉, 在分析 时我们剔除了个别繁殖季节出现的冬候鸟和非繁 殖季节出现的夏候鸟取食数据。同时将每个季节中 取食行为记录少于 5 天的鸟类数据舍去。这些鸟在 这一时期基本上都是样地内的偶见鸟, 对群落内资 源的分割和利用影响较小。整理后, 用于季节间取 食行为变化和集团分析的鸟类共 32 种, 其中留鸟 18 种, 冬候鸟 6 种, 夏候鸟 8 种。

将 32 种鸟的 22 项取食行为频次, 转换为各类 资源利用的行为百分比数据。利用生态数据分析软 件（PC-ORD 4.5) 通过聚类分析方法进行二个季节
取食集团的结构分析, 聚类指标采用欧式距离, 聚 类方法采用离差平方和法 (Ward's method)。聚类 方法的选择主要参考有关文献 (Fan et al, 2008)。 由于留鸟在鹞落坪次生落叶阔叶林中占较大的比 例, 为了研究鸟类取食行为的季节变化对䍃落坪次 生林鸟类集团组成和结构的影响，我们将留鸟在二 个季节的数据加以区分 (在相应的鸟名代码中以数 字 $1 、 2$ 分别表示繁殖季节和非繁殖季节的留鸟)。 将 18 种留鸟二个季节的数据以及 6 种冬候鸟和 8 种夏候鸟的资源利用的行为百分比数据矩阵输入 PC-ORD 分析软件进行 DCA 分析, 用前二个轴上 的排序结果分析资源利用的季节特征和取食行为 变化趋势。用 SPSS13.0 统计软件的多因素方差分 析方法, 检验两个季节间留鸟取食行为的差异性。

\section{2 结 果}

\section{1 乌类集团结构的季节变化}

鹞落坪次生林两个季节的鸟类群落可分为若 干个取食集团。在非繁殖季节, 鸟类群落可以分为 4 个集团（图 1a）。

地面取食集团：由白额燕尾（Enicurus leschenaulti)、蓝巫（Latoucheornis siemsseni）、勺 鸡 (Pucrasia macrolopha) 3 种鸟组成。它们以探取 或拾取的方式取食地面枯枝落叶层下的食物, 处于 群落垂直层的最下层。

灌从取食集团: 由画眉 (Garrulax canorus)、 棕头鸦雀 (Paradoxornis webbianus)、黄喉巫

(Emberiza elegans)、棕颈钩嘴鹋 (Pomatorhinus ruficollis)、灰眭雀鹋 (Alcippe morrisonia)、领雀嘴 軼（Spizixos semitorques）、红胁蓝尾鸲（Tarsiger cyanurus） 7 种鸟组成。以拾取为主, 取食灌从中的 食物, 它们处于群落垂直层的稍高层。

树干 (枝) 取食集团: 由大斑豚木鸟 (Picoides major)、灰头绿豚木鸟 (Picus canus) 和斑姬豚木 鸟 (Picumnus innominatus) 3 种鸟组成。大斑豚木 鸟和灰头绿豚木鸟以探取的方式取食树干里面的 昆虫, 而斑姬豚木鸟则以探取的方式取食枝条中的 昆虫, 它们处于群落垂直层中更高的一个位置。

冠层取食集团: 由大山雀 (Parus major)、红 嘴蓝鹊（Urocissa erythrorhyncha）、松鸦（Garrulus glandarius)、燕雀 (Fringilla montifringilla)、普通 鸩 (Sitta europaea)、红头长尾山雀 (Aegithalos concinnus)、黄腹山雀 (Parus venustulus)、斑冻 


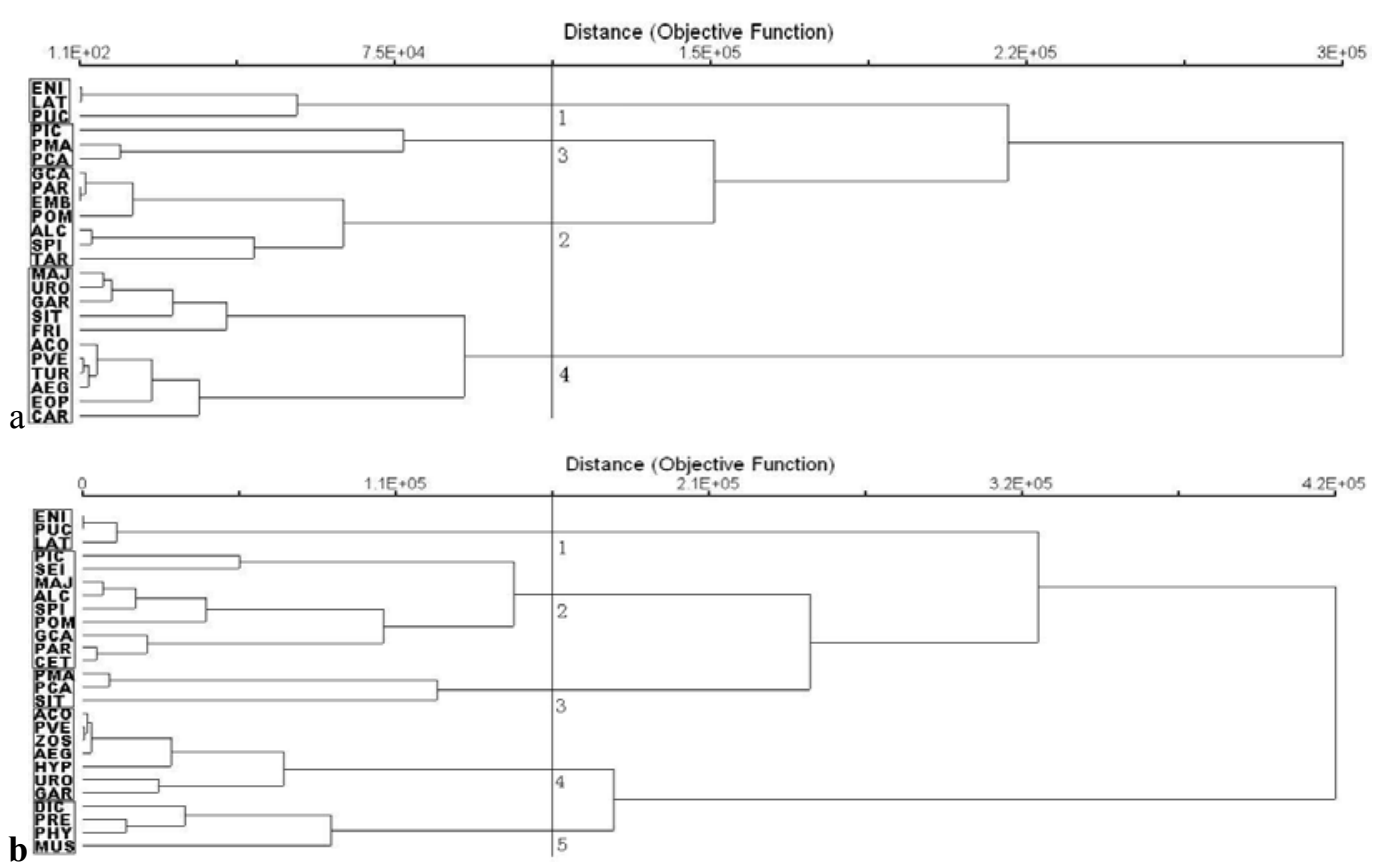

图 1 鹞落坪次生林群落鸟类群落取食集团结构聚类分析结果

Fig. 1 Cluster dendrogram of the foraging guild structure of bird community in Yaoluoping National Natural Reserve $a$, 非繁殖季节; $b$, 繁殖季节。

1 地面取食集团; 2 灌从取食集团； 3 树干（枝）取食集团； 4 冠层取食集团； 5 空中取食集团。

ENI:白额燕尾; LAT: 蓝鸥; PUC： 勺鸡；PIC：斑姬豚木鸟；PMA：大斑豚木鸟；PCA：灰头绿豚木鸟；GCA：画眉; PAR：棕头鸦雀；

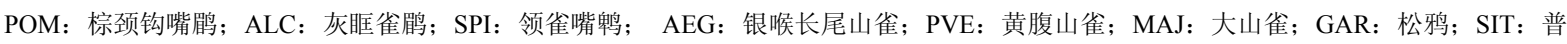

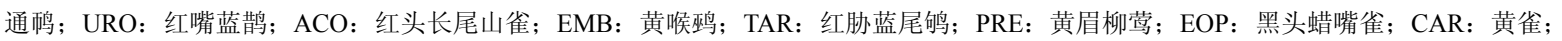

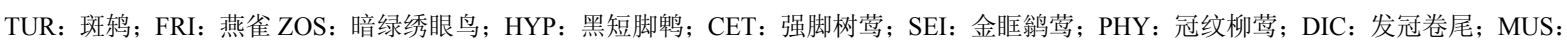
乌暡。

a, Non-breeding season; b, Breeding season.

1 Ground forager; 2 Shrub forager ; 3 Trunk or branch forager; 4 Canopy forager; 5 Air feeder.

ENI: Enicurus leschenaulti; LAT: Latoucheornis siemsseni; PUC: Pucrasia macrolopha; PIC: Picumnus innominatus; PMA: Picoides major; PCA: Picus canus; GCA: Garrulax canorus; PAR: Paradoxornis webbianus; POM: Pomatorhinus ruficollis; ALC: Alcippe morrisonia; SPI: Spizixos semitorques; AEG: Aegithalos caudatus; PVE: Parus venustulus; MAJ: Parus major; GAR: Garrulus glandarius; SIT: Sitta europaea; URO: Urocissa erythrorhyncha; ACO: Aegithalos concinnus; EMB: Emberiza elegans; TAR: Tarsiger cyanurus; PRE: Phylloscopus inornatus; EOP: Eophona personata; CAR: Carduelis spinus; TUR: Turdus eunomus, FRI: Fringilla montifringilla, ZOS: Zosterops japonica; HYP: Hypsipetes leucocepalus; CET: Cettia fortipes; SEI: Seicercus burkii; PHY: Phylloscopus reguloides; DIC: Dicrurus hottentottus, MUS: Muscicapa sibirica.

（Turdus eunomus）、银喉长尾山雀（Aegithalos caudatus)、黄雀 (Carduelis spinus)、黑头蜡嘴雀

(Eophona personata) 等 11 种鸟组成, 其中 4 种是 冬候鸟。主要以拾取的方式取食群落树冠层的食 物, 它们处于群落垂直层最高的位置。

在繁殖季节, 鹞落坪次生林群落内鸟类可以分 成 5 个集团（图 1b)。

地面取食集团: 由白额燕尾、勺鸡、蓝婎 3 种 鸟组成。与非繁殖季节一样, 它们也是以探取或拾 取的方式取食地面枯枝落叶层下的食物。

灌丛取食集团: 由斑姬啄木鸟、金眭鹃莺 (Seicercus burkii）、大山雀、灰眀雀䴗、领雀嘴鹎、 棕颈钩嘴鹛、画眉、棕头鸦雀、强脚树茑 (Cettia fortipes） 9 种鸟组成。其中, 多数鸟都是以拾取的 方式取食灌从中的食物，而斑姬啄木鸟和金眭能莺 分别以探取和飞取的方式取食。

树干（枝）取食集团：由大斑豚木鸟、灰头绿 豚木鸟、普通鸩 3 种鸟组成。与非繁殖季节相似, 两种豚木鸟以探取的方式取食树干里面的食物, 普 通鸩则主要以拾取方式在树干表面取食。 冠层取食集团: 由红头长尾山雀、黄腹山雀、暗绿 绣眼岛 (Zosterops japonica)、银喉长尾山雀、黑短 脚唡 (Hypsipetes leucocepalus)、红嘴蓝鹊、松鸦 7 种鸟组成。这一集团的鸟类, 主要以拾取的方式取 食群落树冠层的食物。

空中取食集团: 由发冠卷尾（Dicrurus 


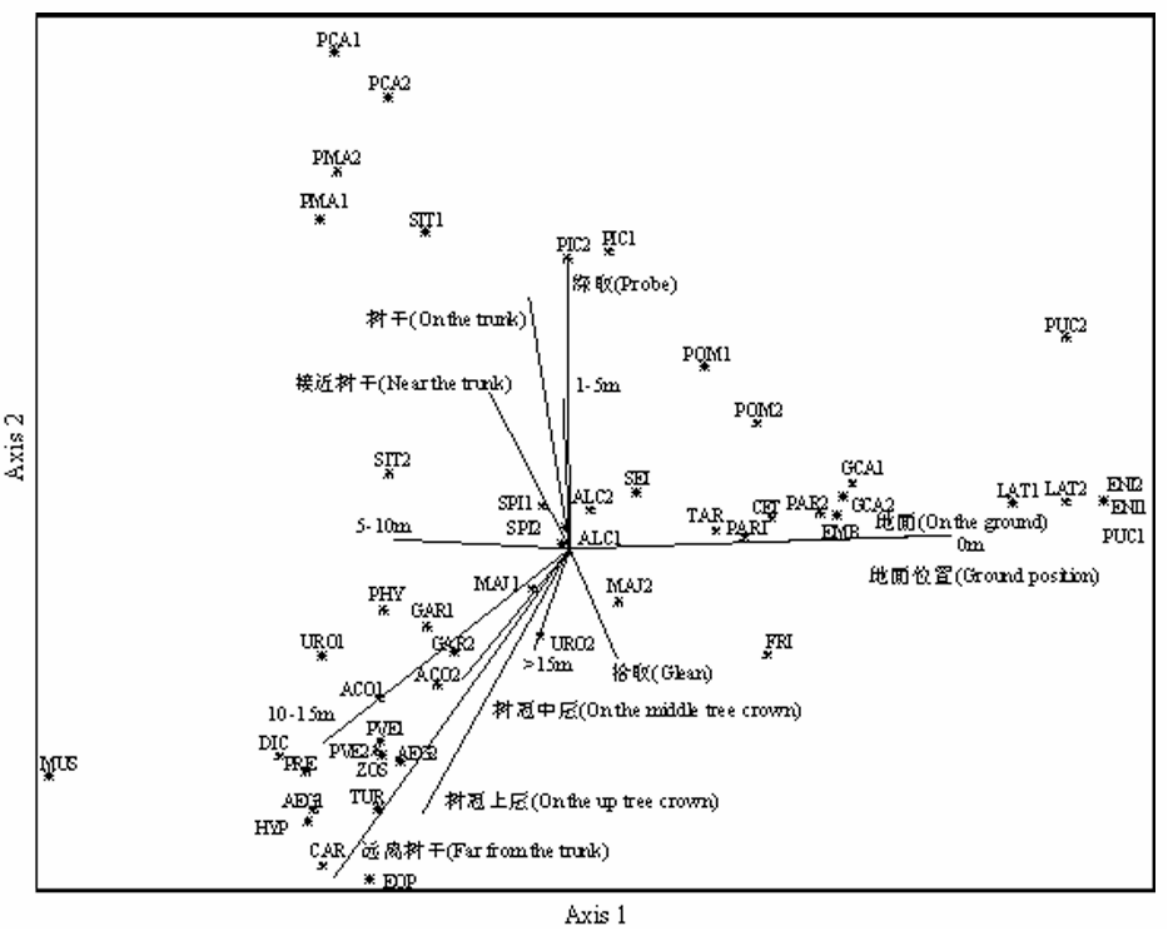

图 2 暚落坪次生阔叶林鸟类群落两个季节鸟类资源利用的 DCA 分析

Fig. 2 The distribution of birds along the two axes of the DCA and the change in foraging pattern of the birds in the community in Yaoluoping National Natural Reserve.

代码后的数字 1 表示繁殖季节, 2 表示非繁殖季节。

Bird in breeding season was indicated by 1 , non-breeding season indicated by 2 .

hottentottus)、黄眉柳莺 (Phylloscopus inornatus)、 冠纹柳莺 ( Phylloscopus reguloides)、乌翁

(Muscicapa sibirica) 4 种鸟组成。这一集团的鸟 类主要以飞取或者出击的方式, 捕捉空中的昆虫。

\section{2 鸟类资源利用的季节变化}

用两个季节的 32 种鸟类取食行为百分比数据 进行无倾向对应分析 (DCA) (表 1) 表明, 第一轴 与变量地面位置 $(r=0.846 ; P<0.01)$ 、地面 $(r=0.850$; $P<0.01) 、 0 \mathrm{~m}(r=0.849 ; P<0.01) 、 0-1 \mathrm{~m}(r=0.413$; $P<0.01)$ 极显著正相关; 与变量远离树干 $(r=-0.669$; $P<0.01) 、 5-10 \mathrm{~m}(r=-0.578 ; P<0.01) 、 10-15 \mathrm{~m}$ $(r=-0.685 ; P<0.01) 、$ 树冠上层 $(r=-0.528 ; P<0.01)$ 极显著负相关, 其中, 正相关系数最大的为地面 $(r=0.850)$, 负相关系数最大的为 $10-15 \mathrm{~m}$ $(r=-0.685)$, 第一轴主要代表鸟类取食高度的变化 信息, 靠近第一轴左边的是取食高度比较大的鸟 类, 靠近右边的是靠近地面取食的岛类。第二轴与 探取（ $r=0.743 ; P<0.01) 、$ 树干 $(r=0.691 ; P<0.01)$ 、 接近树干 $(r=0.543 ; P<0.01)$ 等多数变量极显著正 相关, 与变量远离树干 $(r=-0.791 ; P<0.01)$ 、树冠 上层 $(r=-0.710 ; P<0.01) 、 10-15 \mathrm{~m} （ r=-0.607$;
$P<0.01$ ) 等极显著负相关，其中，正相关系数最大 的为探取 $(r=0.743)$, 负相关系数最大的是远离树 干 $(r=-0.791)$, 第二轴主要代表鸟类取食位置的变 化信息，靠近第二轴上方的是在接近树干位置以探 取方式取食的鸟类, 靠近第二轴下方的是在远离树 干位置取食的鸟类。第三轴与飞取 $(r=0.633$; $P<0.01) 、$ 灌从 $(r=0.726 ; P<0.01) 、 小$ 枝 $(r=0.721$; $P<0.01)$ 等变量极显著正相关，与拾取 $(r=-0.518$; $P<0.01)$ 、树冠上层 $(r=-0.513 ; P<0.01) 、>15 \mathrm{~m}$ $(r=-0.425 ; P<0.01)$ 等变量极显著负相关。其中, 正相关系数最大的变量是灌丛 $(r=0.726)$; 负相关 系数最大的变量是拾取 $(r=-0.518)$, 第三轴主要代 表鸟类取食基质和取食方式变化信息。

2 个 DCA 轴排序结果表明, 在代表鸟类取食高 度信息的第一轴方向上发生变化的鸟类有蓝鸤、棕 头鸦雀、大山雀、红嘴蓝鹊、灰头绿豚木鸟、红头 长尾山雀等 (图 2)。蓝鸥在两个季节取食方式、取 食位置、取食基质和取食高度变化均不显著

$(P>0.05)$; 在取食高度上, 繁殖季节蓝隶利用 $0-5$ $\mathrm{m}$ 高度的比例 (25.9\%) 要大于非繁殖季节 (11.1\%), 而繁殖季节利用地面食物的比例 (74.1\%) 则要比 
非繁殖季节小 (88.9\%) (见附表 1)。因此, 蓝鸥在 第一轴上表现为在繁殖季节更靠近左边。棕头鸦雀 在两个季节的 4 个取食维度上变化也均不显著 $(P>0.05)$; 在取食高度上, 繁殖季节利用 $0-5 \mathrm{~m}$ 高度的比例 $(91.4 \%)$ 大于在非繁殖季节 $(80.9 \%)$

(见附表 1)。因此, 在第一轴上表现为: 棕头鸦雀 在繁殖季节更靠近左边。红嘴蓝鹊两个季节的取食 方式和取食基质变化不显著 $(P>0.05)$, 而取食位置 和取食高度变化显著 $(0.01<P<0.05)$ 。在取食高度 上, 繁殖季节红嘴蓝鹊的取食高度集中在 10-15m $(100 \%)$, 而在非繁殖季节其取食高度的范围扩大， 也利用较低高度的食物 (见附表 1)。因此, 红嘴蓝 鹊在第一轴上表现为在繁殖季节更靠近左边。大山 雀在两个季节的 4 个取食维度的变化均不显著 $(P>0.05)$, 在取食高度上, 繁殖季节大山雀利用 $10-15 \mathrm{~m}$ 的食物比例 (19.5\%) 大于非繁殖季节 (17.5\%)（见附表 1)。因此, 大山雀第一轴上表现 为在繁殖季节更靠近左边。灰头绿豚木鸟的取食高 度在两个季节的变化达到显著水平 $(0.01<P<0.05)$, 其他 3 个取食维度的变化不显著 $(P>0.05)$, 在繁殖
季节利用 5-10m 高度的比例 (60.3\%) 大于非繁 殖季节 (19.5\%)（见附表 1)。所以，灰头绿豚木鸟 在第一轴上表现为在繁殖季节更靠近左边 (图 2)。 而红头长尾山雀的 4 个取食维度在两个季节的变化 均不显著 $(P<0.05)$, 在繁殖季节利用 $10-15 \mathrm{~m}$ 高 度的比例 $(44.8 \%)$ 大于非繁殖季节 $(31.0 \%$ ) (见 附表 1)。因此在第一轴上表现为在繁殖季节也更靠 近左边。

在第二轴方向上发生变化的鸟类主要有勺鸡、 普通鸩、大斑豚木鸟和银喉长尾山雀 (图 2)。其中 勺鸡的取食位置、取食基质和取食高度在两个季节 均无变化; 而取食方式在两个季节差异极显著 $(P<0.01)$ ，繁殖季节以探取方式取食 $(100 \%)$ ，而 在非繁殖季节以探取方式取食比例减小 $(86.7 \%)$, 也以拾取方式取食 (13.3\%)（见附表 1)。普通鸩的 取食方式在两个季节变化不显著 $(P>0.05)$, 取食位 置、取食基质在两个季节的变化均显著 $(0.01<$ $P<0.05)$, 取食高度的变化则达到极显著水平 $(P<0.01)$; 在取食位置上, 繁殖季节在接近树干的 位置取食比例 $(100 \%)$ 大于非繁殖季节 $(55.6 \%)$

表 1 各取食变量与 DCA 前三轴的相关性系数

Tab. 1 Pearson Correlations between foraging variables and the first three axes of the DCA

\begin{tabular}{|c|c|c|c|}
\hline & 第一轴 Axis1 & 第二轴 Axis2 & 第三轴 Axis3 \\
\hline \multicolumn{4}{|l|}{ 取食方式 Foraging pattern } \\
\hline 拾取 Glean & $0.298^{*}$ & $-0.455^{* *}$ & $-0.518^{* *}$ \\
\hline 探取 Probe & -0.070 & $0.743^{* *}$ & 0.059 \\
\hline 飞取 Hover & -0.189 & -0.200 & $0.633^{* *}$ \\
\hline 出击 Attack & $-0.333^{*}$ & -0.203 & 0.253 \\
\hline \multicolumn{4}{|l|}{ 取食位置 Foraging position } \\
\hline 远离树干 Far from the trunk & $-0.669^{* *}$ & $-0.791^{* *}$ & -0.163 \\
\hline 接近树干 Near the trunk & $-0.389^{* *}$ & $0.543^{* *}$ & $-0.398^{* *}$ \\
\hline 灌从 Shrub & $0.321^{*}$ & 0.230 & $0.726^{* *}$ \\
\hline 地面位置 Ground position & $0.846^{* *}$ & 0.156 & -0.163 \\
\hline \multicolumn{4}{|l|}{ 取食基质 Foraging matrix } \\
\hline 树冠上层 On the up crown & $-0.528^{* *}$ & $-0.710^{* *}$ & $-0.513^{* *}$ \\
\hline 树冠中层 On the middle crown & $-0.450^{* *}$ & $-0.496^{* *}$ & 0.006 \\
\hline 树冠下层 On the low crown & $-0.325^{*}$ & -0.213 & 0.105 \\
\hline 小枝 Sprig & $0.322^{*}$ & 0.153 & $0.721^{* *}$ \\
\hline 粗枝 Asperata & -0.057 & $0.314^{*}$ & -0.011 \\
\hline 树干 On the trunk & -0.277 & $0.691^{* *}$ & -0.224 \\
\hline 地面 Ground & $0.850^{* *}$ & 0.160 & -0.170 \\
\hline 空中 Air & $-0.345^{*}$ & -0.216 & 0.259 \\
\hline \multicolumn{4}{|l|}{ 取食高度 Foraging height (m) } \\
\hline 0 & $0.849^{* *}$ & 0.162 & -0.172 \\
\hline $0-1$ & $0.413^{* *}$ & 0.115 & $0.445^{* *}$ \\
\hline $1-5$ & -0.111 & $0.533^{* *}$ & $0.329 *$ \\
\hline $5-10$ & $-0.578^{* *}$ & 0.138 & -0.005 \\
\hline $10-15$ & $-0.685^{* *}$ & $-0.607^{* *}$ & -0.272 \\
\hline$>15$ & -0.257 & $-0.435^{* *}$ & $-0.425^{* *}$ \\
\hline
\end{tabular}

${ }^{*} 0.01<P<0.05 ;{ }^{* *} P<0.01$ (Pearson correlation test). 
(见附表 1)。因此, 两个季节普通鸩在 DCA 第二 轴上发生上下移动 (图 2)。银喉长尾山雀的取食方 式、取食位置、取食基质在两个季节的变化也均不 显著 $(P>0.05)$; 在取食位置上, 繁殖季节在接近树 干的位置取食比例 $(0.0 \%)$ 小于非繁殖季节 $(6.0 \%)$ (见附表 1)。大斑豚木鸟的 4 个取食维度在两个季 节变化也均不显著 $(P>0.05)$; 在取食位置上, 繁殖 季节在接近树干的位置取食比例 $(76.5 \%)$ 小于非 繁殖季节 (87.5\%)（见附表 1)。

\section{3 讨 论}

\section{1 暚落坪次生林植被与鸟类集团划分的关系}

不同环境、地区、群落演替阶段常具有不同的 集团结构, 并且集团的划分存在很大的主观因素 (Zhou, 1987)。但是鸟类集团的结构很大程度上取 决于植被的结构 (Richard et al, 1998; Ding et al, 2007)。植被结构比较复杂的群落如常绿阔叶林, 拥有较高的生物量, 垂直分层明显, 小生境比较复 杂, 与此相适应, 群落内鸟类的集团结构和组成都 比较复杂 (Liu \& Han, 2008); 而一些人工林群落中, 由于植被的垂直结构单一, 导致鸟类的集团组成和 结构也不丰富 (Hou et al, 2000)。

暚落坪地区的次生林具有由北亚热带向暖温 带过渡的特点, 研究样地的群落处于演替中前期, 植被冠层结构与常绿阔叶林相比, 相对比较简单。 植被的垂直层次分为地面层、灌木层和乔木层, 比 较明显, 与此相适应, 鸟类群落也可以分为地面取 食、灌木取食、冠层取食集团; 但是所选样地中, 在同一垂直层片内, 植被结构却相对比较简单, 因 此, 暚落坪次生林中鸟类集团结构相对简单, 树冠 层取食集团没有常绿阔叶林群落那么层次鲜明。鸟 类集团的划分虽然有较大的主观因素, 但是基本能 够反映实际情况, 反映群落内植被的垂直层次和复 杂程度。

\section{2 乌类季节动态对集团结构的影响}

许多研究表明, 候鸟的迁入和迁出影响鸟类的 集团组成, 但对集团结构的影响则是不同的, 产生 的结果也不尽相同 (Almeida \& Granadeiro, 2000;

Wagner, 1981)。在有的地区的鸟类群落中, 鸟类 集团组成受候鸟迁入和迁出的影响较大, 但是集团 结构在一年四季中却不发生变化。而有些地区乌类 群落由于留鸟的取食方式的显著变化和大量候鸟 的迁入和迁出, 不仅鸟类集团的组成发生变化, 而
且集团结构也发生变化 (Casenave et al, 2008; Marone, 1992)。

在鹞落坪次生林群落中, 冬候鸟和夏候鸟对鸟 类集团组成和结构的影响较大。在非繁殖季节, 冬 候鸟主要影响冠层取食集团和灌从取食集团的组 成。黑头蜡嘴雀、斑鸫、燕雀、黄雀等树冠取食的 鸟类在非繁殖季节迁入群落, 由于这几种鸟都在群 落的树冠层取食, 因而使得冠层取食集团组成变得 复杂。而冬候鸟红胁蓝尾鸲和黄喉鸧主要在灌从的 位置以飞取或者拾取的方式获得食物, 因此, 它们 的加入改变了灌从取食集团的组成。冬候鸟的迁入 对非繁殖季节集团的结构变化无影响, 未产生新的 集团。

夏候鸟主要影响繁殖季节冠层取食集团和灌 从取食集团。小型鸟类金睈能莺、强脚树莺等在灌 丛位置以飞取或者拾取方式获得食物, 它们在繁殖 季节加入灌从取食集团，使得该集团组成变复杂; 夏候岛的迁入使得繁殖季节出现了一个全新的取 食集团一一空中取食集团, 这是因为像乌能、发冠 卷尾和柳茑能够以飞取或者出击的方式取食空中 或其他基质中的食物，这与非繁殖季节的鸟类集团 结构是不同的。

\section{3 乌类资源利用变化对集团结构的影响}

在不同季节的森林群落内, 当食物资源如食物 的类型、大小和空间分布等发生变化时, 一些具有 相似取食方式的鸟类, 就会改变取食策略, 来增加 或者降低对食物利用的重叠程度, 从而引起取食方 式的变化 (Alatalo, 1980; Wagner ,1981; Cale, 1994)。 鸟类通过改变自身的取食行为方式来适应食物资 源分布的变化, 引起群落内取食集团结构的变动

(Holmes \& Schultz, 1988; Adams \& Morrison, 1993 ), 出现同一种鸟类在不同的季节属于不同取 食集团的情况 (Gao et al, 1990; Casenave et al, 2008)。

在暚落坪次生林群落中, 由于发冠卷尾、冠纹 柳莺、乌能等在繁殖季节主要以飞取和出击的方式 取食, 这种取食方式的差异导致一个新集团在繁殖 季节出现, 从而改变了集团的结构。留鸟中句鸡的 取食方式变化较大, 其取食方式在繁殖季节以探取 为主 $(100 \%)$ ，而在非繁殖季节则还以拾取的方式 取食 $(13.3 \%)$, 但是, 取食方式的改变没有影响集 团结构, 它一直保留于地面取食集团之中。同样, 虽然红嘴蓝鹊、黄腹山雀、灰头绿豚木鸟和银喉长 
尾山雀的取食高度在两个季节都发生显著变化 $(P>0.05)$, 但未影响集团组成和结构的变化, 它们 在不同季节始终保留在同一集团。而斑姬豚木鸟取 食位置的改变使得它在不同季节属于不同的集团。 在繁殖季节主要在灌从位置取食 $(100 \%)$, 而在非 繁殖季节则扩大了取食位置的范围, 也较多的利用 其他位置的食物资源。大山雀在不同的季节属于不 同的取食集团。比较其两个季节的取食行为, 发现 大山雀在非繁殖季节除了利用冠层的食物之外, 还 利用地面上的食物, 而繁殖季节则较多地利用灌丛 食物。普通鸩在繁殖季节和非繁殖季节取食位置、 取食基质差异显著 $(0.01<P<0.05)$, 取食高度差异

\section{参考文献:}

Adams EM, Morrison ML. 1993. Effects of forest stand structure and composition on red-breasted nuthatches and brown creepers [J]. Journal of Wildlife Management, 57: 616-629.

Alatalo RV. 1980. Seasonal dynamics of resource partitioning among foliage-gleaning passerines in northern Finland [J]. Oecologia, 45: 190-196.

Almeida J, Granadeiro JP. 2000. Seasonal variation of foraging niches in a guild of passerine birds in a cork-oak woodland [J]. Ardea, 88: 243-252.

Blondel J. 2003. Guilds or functional groups: Does it matter? [J]. Oikos, 100: 223-231.

Cale P. 1994. Temporal changes in the foraging behaviour of insectivorous birds in a Sclerophyll forest in Tasmania [J]. EMU, 94: 116-126.

Casenave JLD, Cueto VR, Marone L. 2008. Seasonal dynamics of guild structure in a bird assemblage of the central Monte desert [J]. Basic and Applied Ecology, 9: 78-90.

Ding TS, Liao HC, Yuan HW. 2007. Breeding bird community composition in different successional vegetation in the mountain coniferous forest zone of Taiwan [J]. Forest Ecology and Management, 255: 2038-2048.

Fan XS, Hu DF, Chen HZ, Wang F, Su X. 2008. Study on bloc structure and econiche character- istics of bird communities in the farming areas in north China plain[J]. Ard Zone Research, 25(4): 544-549. [范喜顺, 胡 德夫, 陈合志, 王 峰, 苏 金鐘. 2008. 华北平原耕作区鸟类群落的 集团结构及生态位. 干旱区研究, 25 (4) : 544-549.]

Gao W, Xiang GQ, Shang JC, Feng HL. 1990. On the guild structure and its relationship of secondary forest bird community [J]. Journal of Northeast Forestry University, 18(8): 114-125. [高 玮, 相桂权, 尚 金城, 冯贺林. 1990. 山地次生林鸟类集团结构及关系的研究. 东北 林业大学学报, 18 (8) : 114-125.]

Holmes RT, Schultz JC. 1988. Food availability for forest birds: Effects of prey distribution and abundance on bird foraging [J]. Canadian Journal of Zoology, 66: 720-728.

Hou JH, Wu ML, Hu YF, Zhang XZ, Hu ZT. 2000. A study on the vertical space patterns of bird community in Mulanweichang forest park[J]. Journal of Agricultural University of Hebei, 23 (1): 78-81. [侯建华, 武明录, 胡永富, 张向忠, 胡振天. 2000 . 木兰围场国家森林公园鸟
极显著 $(P<0.01)$, 因此在两个季节中分别属于树干 (枝) 取食集团和冠层取食集团 (图 2)。由此可见, 在不同季节, 鹞落坪次生林内鸟类的取食方式、取 食位置、取食基质和取食高度都在发生不同程度的 变化。鸟类正是通过改变自身的取食行为特点来适 应不断变化的食物资源分布, 进行次生林群落资源 分割, 在群落中共同生存。

致谢: 鹞落坪国家级自然保护区储勇、李文革、 沈千存、刘涁等在野外工作期间给予大力支持和帮 助, 一并感谢!

类群落垂直空间格局研究. 河北农业大学学报, 23 (1) : 78-81.]

Hou JH, Wu ML, Hu YF, Zhang XZ, Hu ZT. 2001. Study on the bird community structure in the forest-steppe transition zone [J]. Acta Zoological Sinica, 47 (special issue): 148-156. [侯建华, 武名录，胡 永福, 张向忠, 胡振天. 2001. 森林/草原过渡地带鸟类群落空间结 构研究. 动物学报, 47 (专刊) : 148-156.]

Jaksic FM. 1981. Abuse and misuse of the term "guild" in ecological studies [J]. Oikos, 37: 397-400.

Liu H, Han LX. 2008. Birds foraging guilds in Xujiaba evergreen broad-leaved forest of Ailao Mountain [J]. Zoological Research, 29(5): 561-568. [刘 菡, 韩联宪. 2008. 云南哀牢山徐家坝常绿阔叶林的鸟 类取食集团. 动物学研究, 29 (5) : 561-568.]

Marone L. 1992. Seasonal and year-to-year ?uctuations of bird populations and guilds in the Monte Desert, Argentina [J]. Journal of Field Ornithology, 63: 294-308.

Richard MD, Jay BH, Mariko Y. 1998. Associations between breeding bird abundance and stand structure in the White Mountains, New Hampshire and Maine, USA[J]. Forest Ecology and Management, 103: 217-233.

Wagner JL. 1981. Seasonal change in guild structure: Oak woodland insectivorous birds [J]. Ecology, 62: 973-981.

Xie ZW, Wu GF. 1995. The vegetation types and their distributions in Yaoluoping Natural Reserve of Anhui province [J]. Journal of East China Normal University (Natural Science Edition). 3: 93-100.[谢中 稳, 吴国芳. 1995. 安徽省鹞落坪自然保护区的植被类型及其分布. 华东师范大学学报 (自然科学版) , 3: 93-100.]

Xu H, Qian Y, Peng BZ, Jiang MK. 2003. The evaluation of indirect-use value of biodiversity of yaoluoping nature reserve[J]. Journal of Nanjing Forestry University (Natural Sciences Edition), 27(2): 16-20. [徐 慧, 钱 谊, 彭补拙, 蒋明康. 2003. 鹞落坪自然保护区森林 生态系统间接使用价值评估. 南京林业大学学报 (自然科学版), 27 (2) : 16-20.]

Zhou F. 1987. Guild structure of the forest bird community in Dinghushan [J]. Acta Ecologica Sinica, 7 (2)：176-184. [周 放. 1987. 鼎湖山森 林鸟类群落的集团结构. 生态学报, 7 (2): 176-184.] 


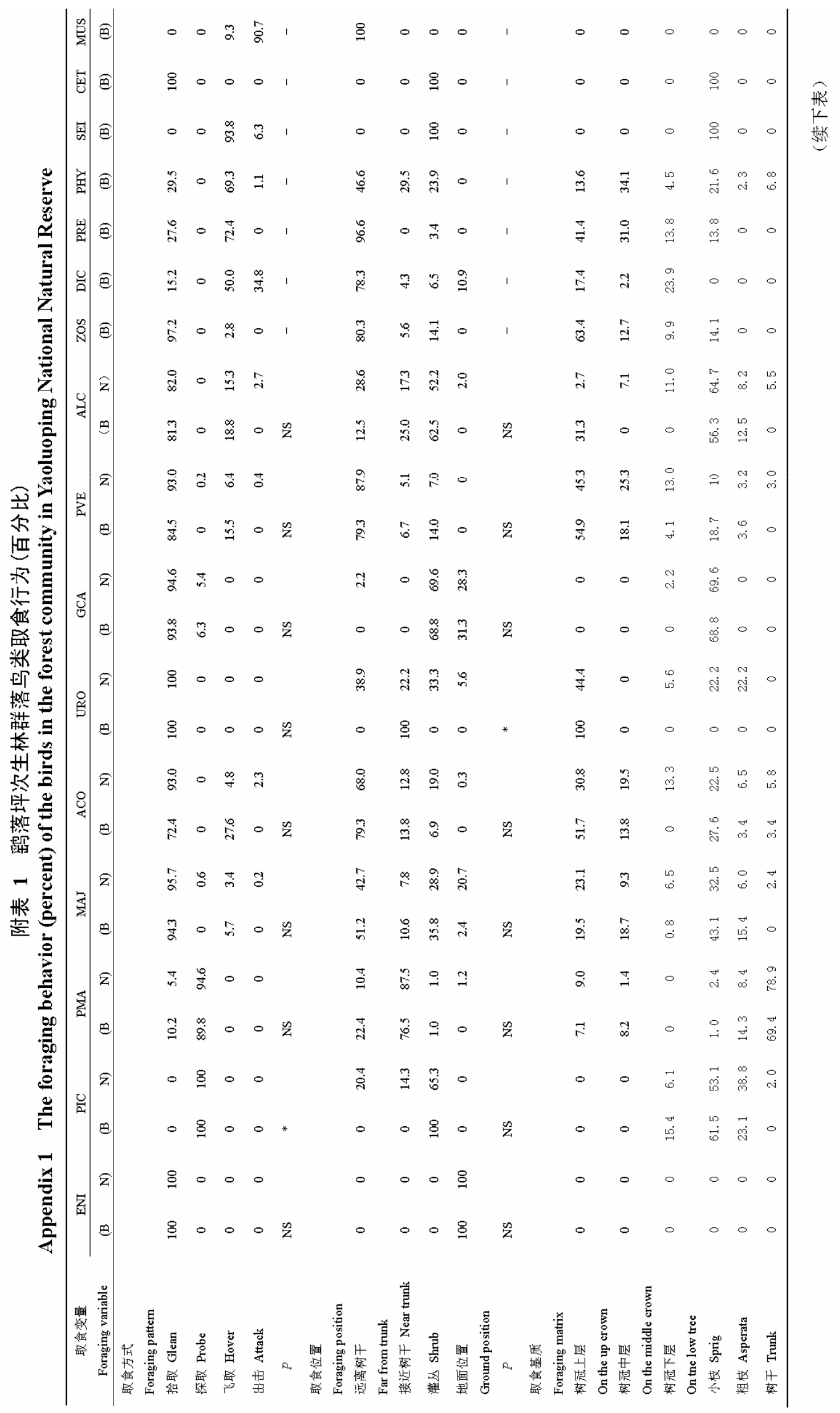




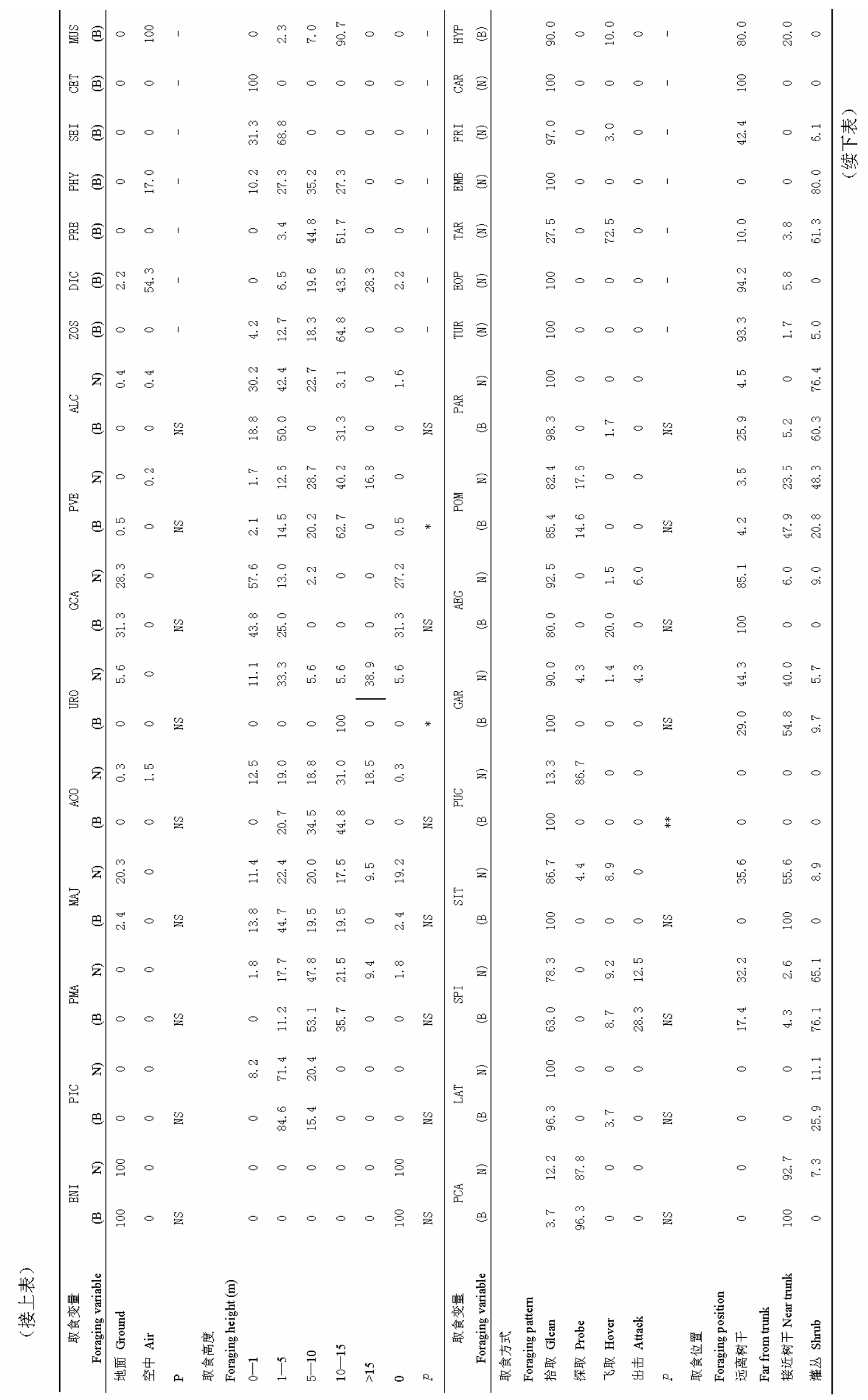




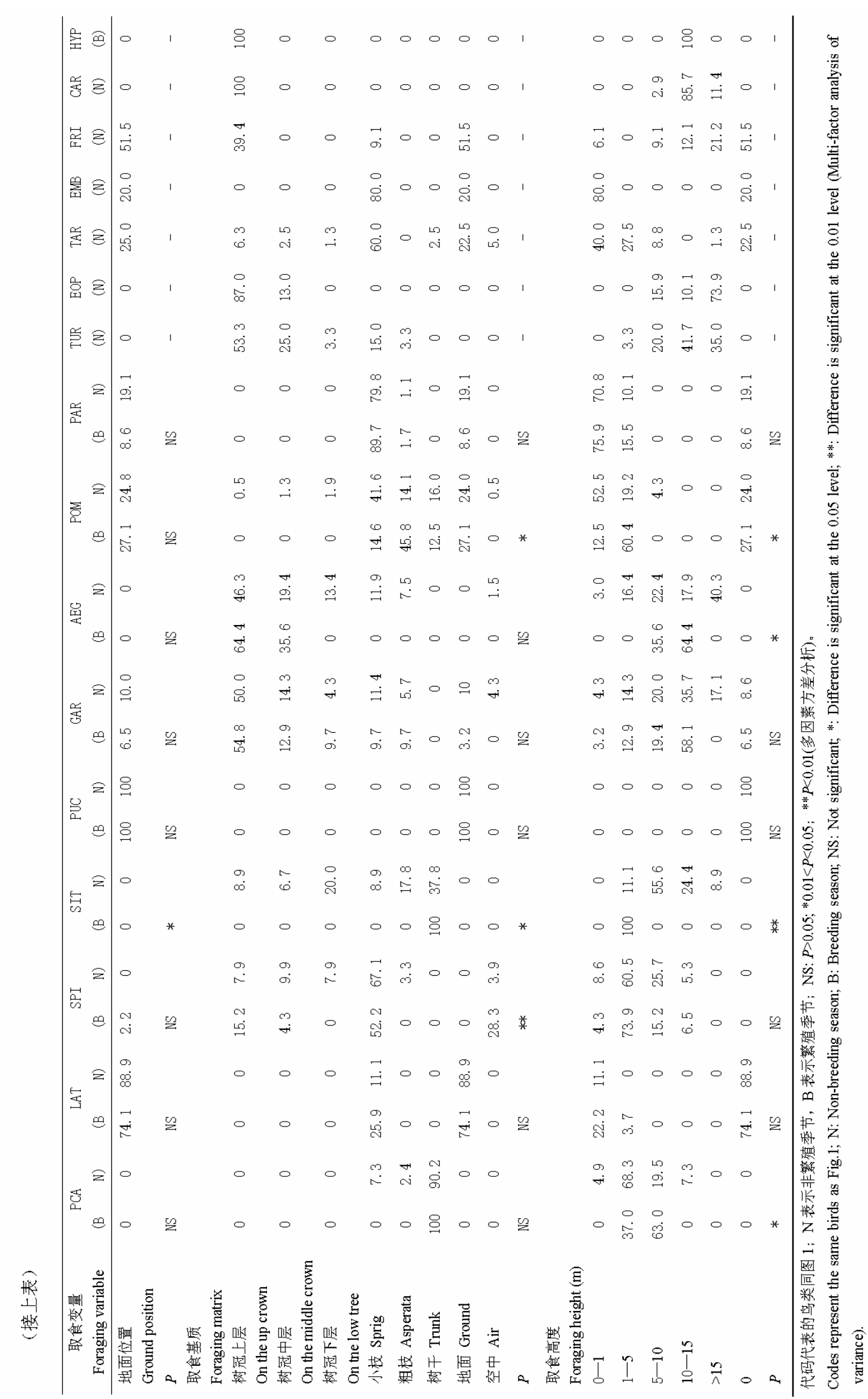

